\title{
Standard values of the upper body posture in male adults
}

\author{
Daniela Ohlendorf ${ }^{1, A-D}$, Frederic Adjami ${ }^{2, B, C, E}$, Benjamin Scharnweber ${ }^{3, B, C, E}$, Johannes Schulze ${ }^{1, D-F}$, \\ Hanns Ackermann ${ }^{4, C, E}$, Gerhard M. Oremek ${ }^{1, E, F}$, Stefan Kopp ${ }^{2, E, F}$, David A. Groneberg ${ }^{1, A, E, F}$ \\ ${ }^{1}$ Institute of Occupational Medicine, Social Medicine and Environmental Medicine, Faculty of Medical Science, Goethe University Frankfurt, Germany \\ ${ }^{2}$ Department of Orthodontics, School of Dentistry, Faculty of Medical Science, Goethe University Frankfurt, Germany \\ ${ }^{3}$ Department of Prosthetics, School of Dentistry, Faculty of Medical Science, Goethe University Frankfurt, Germany \\ ${ }^{4}$ Institute of Biostatistics and Mathematical Modeling, Faculty of Medical Science, Goethe University Frankfurt, Germany \\ A - research concept and design; B - collection and/or assembly of data; $\mathrm{C}$ - data analysis and interpretation; \\ $D$ - writing the article; $E$ - critical revision of the article; $F$ - final approval of the article
}

Address for correspondence

\section{Daniela Ohlendorf}

E-mail: ohlendorf@med.uni-frankfurt.de

\section{Funding sources}

None declared

Conflict of interest

None declared

Received on January 19,2017

Reviewed on March 23, 2017

Accepted on April 25, 2017

\begin{abstract}
Background. Interactions within the musculoskeletal system have been investigated and confirmed in numerous studies.

Objectives. Since there are no standard values for the posture of healthy persons, this study attempts to define reference values for the upper body posture in healthy men.

Material and methods. A 3-dimensional back scan was performed to quantify the upper back posture while habitually standing. Tolerance regions for habitual posture were calculated, including the upper and lower limitfor $95 \%$ of all values. Furthermore, the left and right limit of the confidence interval (CI) was carried out. Group differences were tested by using the t-test or the Wilcoxon-Mann-Whitney $\mathrm{U}$ test.
\end{abstract}

Results. Height, weight and body mass index (BMI) of the participants were comparable to those of the average young German males. The spinal column was marginally twisted to the right. The spinal curves, defined by the thoracic or lumbar flexion angle, and the kyphosis and lordosis angle, indicated that the angle in the thoracic spine area was larger than that in the lumbar region. Consequently, a more kyphotic posture was observed in the sagittal plane. The habitual posture was slightly scoliotic, with a rotational component (scapular depression left, right scapula marginally located more dorsally, high state of pelvic left, iliac left further rotated posteriorly and simultaneously tilted further ventrally). No significant difference between right and left-handed persons could be proven.

Conclusions. Video raster stereography is a suitable method to measure the 3-dimensional back surface. Using this method for healthy young men, we observed that they had an almost ideally balanced posture with minimal ventral body inclination and a marginal scoliotic deviation. The normal values allow a better comparison of data between different studies of body posture.

Key words: standard value, tolerance value, confidence interval, back scan, male subjects

DOI

10.17219/acem/70669

Copyright

Copyright by Author(s)

This is an article distributed under the terms of the

Creative Commons Attribution Non-Commercial License

(http://creativecommons.org/licenses/by-nc-nd/4.0/) 


\section{Introduction}

Interactions between the temporomandibular joints and the spine, pelvis or the lower limbs have been investigated and the values confirmed in numerous studies. ${ }^{1-6}$ This leads to an interdisciplinary treatment of diseases and to a holistic approach to health disorders or diseases.

This has been particularly shown in studies concerning the correlation of dental findings with body posture. Korbmacher et al. proved a correlation between asymmetrical posture in the cervical spine and jaw asymmetry as well as shoulder and pelvis asymmetry (leg length discrepancy) in children. ${ }^{7}$ Similarly, Saccucci et al. described the association of scoliosis with lateral crossbite or a midline shift. ${ }^{8}$ The relationship between a drooping posture and prognathism was already presented by Wachsman in $1960 .{ }^{9}$ Also, Lippold et al. demonstrated significant correlations, but they pointed out that the changes did not follow any systematics with respect to orthopedic findings and dental occlusion in the sagittal plane (Angle's classes). ${ }^{10}$

In patients without subjective cervical, spine and pelvic complaints, Fink et al. indicated an altered passive range of motion and functional limitations of the shoulder, compared to subjects with temporomandibular disorders (TMD). ${ }^{11,12}$ The latter also described increasing joint disc changes and muscle tension in the shoulder, back and pelvic area. Saito et al. also related the posture (plantar arch, lower extremities, pelvis, shoulder and head posture) and temporomandibular joint changes. ${ }^{5}$ When patients with the anterior displacement of the articular disc were compared to a control group without disc displacement, changes were observed in the pelvic, thoracic, lumbar spine, and head position. The authors emphasized that no conclusions could be drawn in terms of cause and effect, but rather the analysis of posture should include more than 1 component in the prevention and management of temporomandibular joint changes. In all studies, correlations were made between body posture and dental findings by comparing different patient groups or by prepost intervention comparison.

Up to now, there have been no standard or reference values for patients in particular; reference values could indicate changes in the posture before treatment and validate changes associated with any dental treatments. Also, classifications, e.g., of the severity of posture deviations, are only possible with standard or reference values. The comparison between the current posture and standard values could provide a description of preexisting changes. These "deviations" could be quantified, e.g., in the form of (parametric or non-parametric) percentiles, similar to the Z- or T-scores of bone density. ${ }^{13}$

The optimal physiological posture is the result of the functional interaction of all body segments, including the head, thorax, spine, and pelvis. When standing or moving, all muscles are used to balance the body. Ideally, the perpendicular line of the body's center of gravity crosses the center of the support surface between the feet, also termed "center of pressure" (CoP). Both feet carry the body weight equally. ${ }^{14}$ Seen from the lateral plane, this vector optimally crosses the external auditory canal, the dens, the anatomical-functional spine transitions, the gravity center at the $2^{\text {nd }}$ sacral vertebra, and then through the hip and knee to the ankle. Any deviation from this optimum leads to disbalance of the weight-bearing structures with a local overload of the musculoskeletal system. ${ }^{14,15}$ This change of the body posture can be measured, e.g., by a 3-dimensional back scan.

Since standard values for the posture of healthy persons are lacking, this study tries to define reference values for the upper body posture in healthy men. These values can be used to categorize the results of other studies and to define tolerance ranges. The back of male subjects in a prone posture was measured by a 3-dimensional back scanner (video scanning stereography); it measured the back geometry between the $7^{\text {th }}$ cervical vertebra and the gluteal cleft. Additional measurements, e.g., of the distance between selected points or angle measurements, are possible. This back scanner has been used in several studies to correlate the upper body static and dental findings. ${ }^{16-19}$

\section{Material and methods}

\section{Subjects}

A total of 102 male volunteers $18-35$ years old (mean age $25.4 \pm 3.6$ years) were included in the study. Their body weight ranged from 57 to $108 \mathrm{~kg}$ (mean $77.2 \pm 10.0 \mathrm{~kg}$ ), their height from 1.54 to $2.02 \mathrm{~m}$ (mean $1.81 \pm 0.07 \mathrm{~m}$ ) and the body mass index (BMI) from 18.8 to $30.5 \mathrm{~kg} / \mathrm{m}^{2}$ (mean $\left.23.6 \pm 2.3 \mathrm{~kg} / \mathrm{m}^{2}\right)$. According to the WHO weight classification, ${ }^{20} 77.4 \%$ of the participants had a normal BMI $\left(18.5-24.9 \mathrm{~kg} / \mathrm{m}^{2}\right), 20.6 \%$ were pre-obese (BMI: $25-29.9 \mathrm{~kg} / \mathrm{m}^{2}$ ) and $2 \%$ of subjects had obesity I $\mathrm{I}^{\circ}$ (BMI: $30-34.9 \mathrm{~kg} / \mathrm{m}^{2}$ ).

All subjects were healthy and free of complaints regarding the musculoskeletal system. Subjects with disorder symptoms in the temporomandibular system were excluded using a questionnaire. ${ }^{21}$

Briefly, $91.2 \%$ of the subjects reported to be right-handed and $8.8 \%$ were left-handed. $72.4 \%$ of the participants were students, $27.6 \%$ were employees in different occupations (dentist, military musicians, professional athletes, office workers).

All subjects volunteered to participate in the investigations. They were informed about the study design before giving written informed consent. The study was in accordance with the 1964 Helsinki Declaration and its later amendments, and was approved by the local medical ethics committee of the Faculty of Medical Science, Goethe University Frankfurt, Germany (approval No. 307/12). 

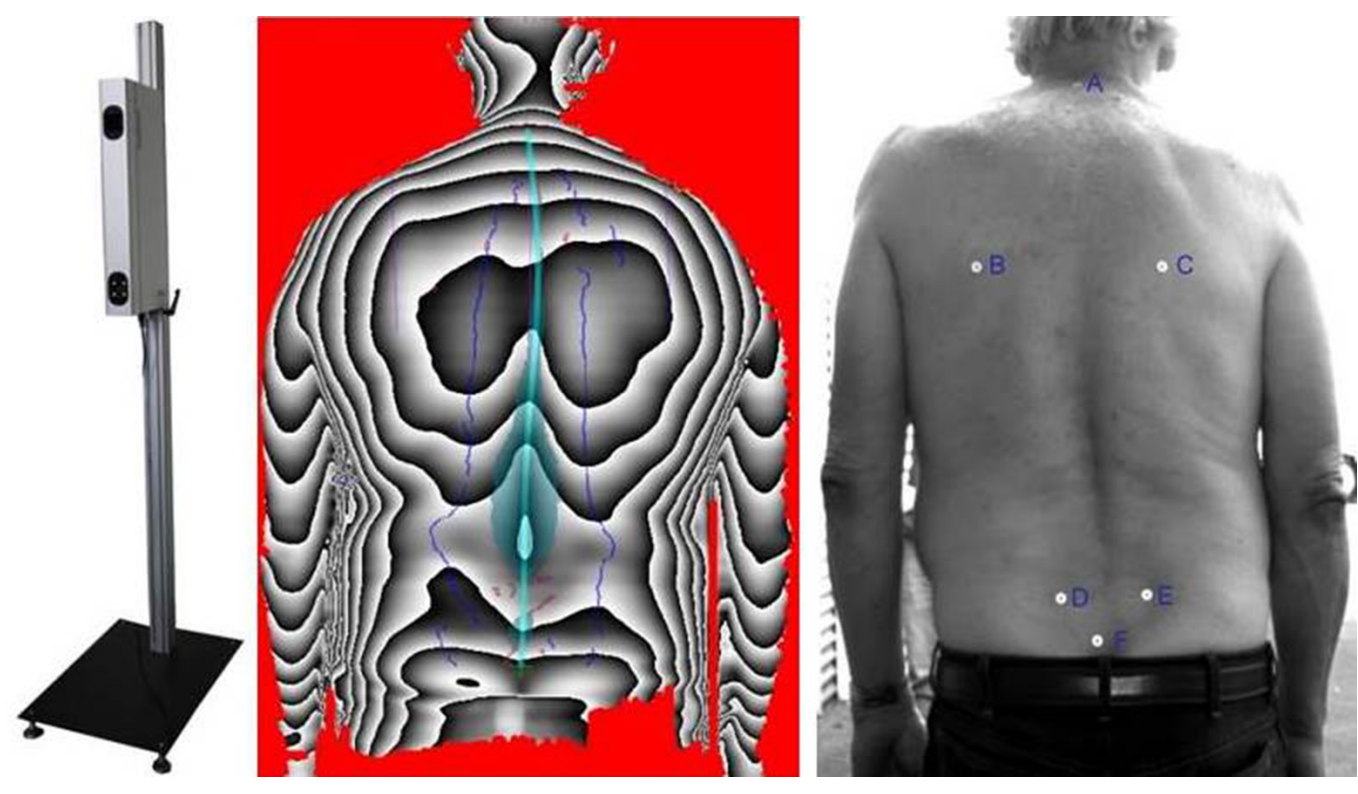

Fig. 1. Back scanner MiniRot Kombi (ABW GmbH, Frickenhausen, Germany); 3-dimensional phase picture of the back and marker position on the back

A - vertebra prominens ( $7^{\text {th }}$ cervical vertebra); B - lower scapular angle left; C - lower scapular angle right; D - spina iliaca posterior superior (SIPS) left; E - spina iliaca posterior superior (SIPS) right; F - sacrum-point (cranial beginning of the gluteal cleft).

\begin{tabular}{|c|c|}
\hline Mark & positions \\
\hline VP & Vertebra prominens \\
\hline & ( $7^{\text {th }}$ cervical vertebra) \\
\hline AISR & Angulus inferior scapulae right \\
\hline & Lower scapular angle right \\
\hline AISL & Angulus inferior scapulae left \\
\hline & $\begin{array}{l}\text { Lower scapular angle left } \\
\text { Spina iliaca posterior superior right }\end{array}$ \\
\hline SIPS R & \\
\hline SP & Sacrum point \\
\hline SIPS L & Spina iliaca posterior superior left \\
\hline
\end{tabular}

Calculated positions

SIPS M Middle point between SIPSL and SIPS R

SM Middle point between the scapular angle AISL and AISR

AM Middle point between the arms

(if arm position indicators were used)

KA Kyposis apex

(dorsal apex with a vertical tangent, approx. Th6)

IP Point with the highest negative surface deflection)

under KA (approx. Th12)

Lordosis apex

(ventral apex at the bottom of a vertical tangent, approx. L2)

Fig. 2. Marked and calculated positions of the back scan

\section{Measurement system}

A 3-dimensional back scan was performed to quantify the upper back posture of a subject standing (Fig. 1). The scan was taken with the MiniRot Kombi system (ABW $\mathrm{GmbH}$, Frickenhausen, Germany), using a projector that projects a zebra pattern on the back, which was videographed. This system represented the back surface in 3 dimensions.

Rotation movements in the shoulder and pelvic area, but also the shape of the spine (lordotic or kyphotic posture as well as a sense of a scoliosis posture), were calculated.

An LCD camera captured the stripe pattern from a defined angle (this angle is determined by the permanent installation of the camera and the projector in the unit). Thus, the back surface was represented as a phase picture, which was analyzed by an integrated software program. To calibrate the phase picture, all test persons were marked at 6 defined anatomical locations as indicated in Fig. 2. Thus, always 2 markers allowed a direct detection of an angle for the spine, the shoulder and the pelvic area (Fig. 2).

A back scan of $2 \mathrm{~s}$ identified and measured the 6 surface markers, including the calculation and representation of the 3-dimensional coordinates in a phase picture. During a movement sequence, 15 photos were shot. The maximal picture frequency of the MiniRot Kombi system is more than $50 \mathrm{fps}$ with a spatial resolution of $1 / 100 \mathrm{~mm}$. The calculation of the 3-dimensional coordinates of the 
back surface is possible with triangulation techniques. The system error is specified as $<1 \mathrm{~mm}$ (manufacturer's information), while the reproducibility is limited by the calculations of the upper body posture being made from the markers directly on the skin $(<0.5 \mathrm{~mm})$. Artifacts may occur due to different patient placements in front of the scanner and have to be avoided, i.e., for each scan the marker location has to be standardized.

\section{Body scans}

The subjects stood barefoot in habitual body and jaw posture, about $90 \mathrm{~cm}$ in front of the back scanner. Their arms were hanging loosely; the subjects looked horizontally at the opposite wall. To measure this position, 3 repeated measurements were taken within $2 \mathrm{~min}$.

\section{Evaluation of parameters}

To quantify the parameters from the back scan, the 3-dimensional phase picture of the back was split into 3 components: spine with markers on the $7^{\text {th }}$ cervical vertebra (C7) and the $3^{\text {rd }}$ lumbar vertebra (L3), shoulder with markers at the top of the scapula, and pelvis with the markers on the left and right spina iliaca posterior superior (SIPS). The marker position is shown in Fig. 2. A list and explanation of the spine parameters are shown in Table 1, those of the pelvis parameters in Table 2, and Table 3 contains the shoulder parameters.

\section{Statistical evaluation}

With the initial Kolmogorov-Smirnov test, the normal distribution can only partly be rejected, so that either parametrical tolerance regions or non-parametrical tolerance

Table 1. Detailed list and explanation of the spine parameters

\begin{tabular}{|c|c|}
\hline \multicolumn{2}{|r|}{ Spine parameter } \\
\hline Trunk length $\mathrm{D}[\mathrm{mm}]$ & spatial distance between the markers VP and DM \\
\hline Trunk length S $[\mathrm{mm}]$ & spatial distance between the markers VP and SP \\
\hline Sagittal trunk decline $\left[{ }^{\circ}\right]$ & $\begin{array}{l}\text { inclination of the trunk length D marked line from the perpendicular to the sagittal plane } \\
\text { tilt anteriorly, flexion (negative values) } \\
\text { tilt dorsally, extension (positive values) }\end{array}$ \\
\hline Frontal trunk decline $\left[^{\circ}\right]$ & $\begin{array}{l}\text { inclination of the trunk length D marked line from the perpendicular to the frontal plane } \\
\text { tilt anteriorly (negative values) = possible lordosis } \\
\text { tilt dorsally (positive values) = possible kyphosis }\end{array}$ \\
\hline Axis decline $\left[^{\circ}\right]$ & $\begin{array}{l}\text { deviation of the line of the area marked by the trunk length } \mathrm{D} \text { line of the } 90^{\circ} \text { rotated distance } \mathrm{DL}-\mathrm{DR} \\
\rightarrow \text { decline between the upper body and the pelvis }\end{array}$ \\
\hline Thoracic bending angle $\left[^{\circ}\right]$ & deviation of the distance VP-KA from the perpendicular \\
\hline Lumbar bending angle $\left[^{\circ}\right]$ & deviation of the distance $K A-L A$ from the perpendicular \\
\hline SD of lateral deviation [mm] & root mean square deviation of the median line of the distance VP-DM \\
\hline Maximal lateral deviation $[\mathrm{mm}]$ & $\begin{array}{l}\text { maximum deviation of the median line of the distance VP-DM } \\
\text { negative values = deviation to the left } \\
\text { positive values = deviation to the right }\end{array}$ \\
\hline $\mathrm{SD}$ of rotation $\left[{ }^{\circ}\right]$ & $\begin{array}{l}\text { root mean square deviation of surface rotation of the median line (torsion of the spinous processes } \\
\text { of the spine) }\end{array}$ \\
\hline Maximal rotation $\left[{ }^{\circ}\right]$ & maximum positive or negative surface rotation of the median line \\
\hline Kyphosis angle $\left[{ }^{\circ}\right]$ & $\begin{array}{l}\text { angle measured in the sagittal plane between the upper IP of the spine at the thoracolumbar and the } \\
\text { IP at VP }\end{array}$ \\
\hline Lordosis angle $\left[{ }^{\circ}\right]$ & angle between the inflection point at DM and the thoracolumbar inflection point IP \\
\hline
\end{tabular}

SIPS - spina iliaca posterior superior; VP - vertebra prominens; DM - middle between dimple (= SIPS) left and dimple (= SIPS) right; SP - sacrum point; $\mathrm{DL}-\mathrm{DR}=$ distance between dimple (= SIPS) left and dimple (= SIPS) right; KA - kyphosis apex; LA - lordosis apex; IP - inflection point (point of the greatest negative surface decline); SD - standard deviation.

Table 2. Detailed list and explanation of the pelvis parameters

\begin{tabular}{|c|c|}
\hline \multicolumn{2}{|r|}{ Pelvis parameter } \\
\hline Pelvis distance $[\mathrm{mm}]$ & spatial distance between SIPS L and SIPS R \\
\hline Pelvis height $\left[{ }^{\circ}\right]$ and $[\mathrm{mm}]$ & decline of the connecting line between SIPS L and SIPS R to the horizontal in the frontal plane \\
\hline Pelvis torsion $\left[{ }^{\circ}\right]$ & $\begin{array}{l}\text { angle between the surface normal at the } 2 \text { dimples SIPS } L \text { and SIPS } R \\
\text { negative differential angle }=\text { normal at point SIPS } L \text { is stronger upward as at point SIPS } R \\
\text { positive difference angle }=\text { normal at point SIPS L is stronger downward as at point SIPS R }\end{array}$ \\
\hline Pelvis rotation $\left({ }^{\circ}\right)$ & rotation of the distance SIPS L-SIPS R in the transversal plane \\
\hline
\end{tabular}

SIPS L - spina iliaca posterior superior left; SIPS R - spina iliaca posterior superior right. 
regions were calculated, defined by the upper and lower limit for $95 \%$ of all values (= $\pm 2 \sigma$ values). These values are results that are found in about $95 \%$ of the examined subjects. Within this tolerance range, all values have to be considered normal, so that the tolerance ranges estimate the central part of $95 \%$ of the measured subject population.

Furthermore, the two-sided 95\% confidence interval (CI) was calculated; it indicates the possible range for the mean or median value depending on the distribution quality and shows the accuracy of these values. For testing group differences, the t-test or the Wilcoxon-Mann-Whitney U test was used. The evaluation of the data was carried out using Bias v. 11.0 (Epsilon Verlag, Darmstadt, Germany).

\section{Results}

The constitutional parameters of body height, body weight and BMI were not normally distributed. The median of body weight was $76.0 \mathrm{~kg}$ (tolerance range: $59.4-98.9 \mathrm{~kg}$; $\mathrm{CI}=74-78 \mathrm{~kg}$ ). For the body height, a median of $1.82 \mathrm{~m}$ was calculated with a tolerance range between 1.64 and $2.00 \mathrm{~m}$ and a CI of $1.80-1.83 \mathrm{~m}$. For the BMI, a median of $23.1 \mathrm{~kg} / \mathrm{m}^{2}$ was calculated, with a corresponding tolerance range from 19.4 to $29.6 \mathrm{~kg} / \mathrm{m}^{2}$ and a CI from 22.6 to $23.8 \mathrm{~kg} / \mathrm{m}^{2}$.

To exclude the influence of handedness on all spine parameters, they were tested in advance using the t-test or the Wilcoxon-Mann-Whitney U test. Not all parameters were significant $(\mathrm{p} \geq 0.05)$.

The posture of an average healthy male was calculated based on the back scan readings. In Table 4 the spine parameters are listed as mean or median values, including tolerance range and CIs. On average, the subjects were slightly inclined in anterior line of $3.66^{\circ}$ (tolerance range: from $8.35^{\circ}$ ventrally to $1.05^{\circ}$ dorsally; CI from $4.12^{\circ}$ to the right to $3.20^{\circ}$ to the left).

Laterally, a minimal deviation of $0.33^{\circ}$ to the right of the frontal trunk decline was observed. The CI $\left(0.00-0.67^{\circ}\right)$ includes the perpendicular position, the tolerance range ranged from $-1,79^{\circ}$ to the left to $2.33^{\circ}$ to the right. Compensatory, the axial deviation (as the inclination between the upper body and the pelvis) was in the mean value slightly tilted to the left $\left(-0.34^{\circ}\right)$, with a tolerance range of $\pm 4^{\circ}$ and $\mathrm{CI}<1^{\circ}\left(-0.78^{\circ}\right.$ and $0.11^{\circ}$, respectively). This

Table 3. Detailed list and explanation of the shoulder parameters

\begin{tabular}{|c|c|}
\hline \multicolumn{2}{|r|}{ Shoulder parameter } \\
\hline Scapular distance $[\mathrm{mm}]$ & distance between lower scapular angle left (AISL) and lower scapular angle right (AISR) \\
\hline Scapular height $\left[{ }^{\circ}\right]$ & $\begin{array}{l}\text { height difference between the points AISL and AISR } \\
\text { positive value = AISR higher than AISL } \\
\text { negative value = AISR deeper than AISL }\end{array}$ \\
\hline Scapular rotation $\left[{ }^{\circ}\right]$ & rotation of the distance $D L-D R$ in the transversal plane \\
\hline Scapular angle left $\left[{ }^{\circ}\right] /$ scapula angle right $\left[{ }^{\circ}\right]$ & $\begin{array}{l}\text { best fit straight line on the shoulders to the horizontal; the center point of the regression line is set } \\
\text { vertically above AISL/AISR } \\
\text { the greater the angle, the more caudally located the shoulder }\end{array}$ \\
\hline
\end{tabular}

AISL - angulus inferior scapulae left; AISR - angulus inferior scapulae right; SIPS - spina iliaca posterior superior; DL-DR - distance between dimple (= SIPS) left and dimple (= SIPS) right.

Table 4. Spine parameters: mean value, median, tolerance ranges (upper and lower limit), confidence intervals (Cls) (left and right limit)

\begin{tabular}{|c|c|c|c|c|c|}
\hline Spine parameter & $\begin{array}{l}\text { Mean value/ } \\
\text { median }\end{array}$ & $\begin{array}{c}\text { Tolerance range } \\
\text { lower limit }\end{array}$ & $\begin{array}{c}\text { Tolerance range } \\
\text { upper limit }\end{array}$ & Cl left limit & $\mathrm{Cl}$ right limit \\
\hline Trunk length D [mm] & 478.42 & 423.19 & 533.66 & 473.03 & 483.82 \\
\hline Trunk length S [mm] & 528.44 & 470.63 & 586.25 & 522.80 & 534.08 \\
\hline Sagittal trunk decline $\left[^{\circ}\right]$ & -3.66 & -8.35 & 1.05 & -4.12 & -3.20 \\
\hline Frontal trunk decline $\left[^{\circ}\right]$ & $0.33^{*}$ & $-1.79^{*}$ & $2.33^{*}$ & $0.00^{*}$ & $0.67^{*}$ \\
\hline Axis decline $\left[^{\circ}\right]$ & -0.34 & -4.87 & 4.20 & -0.78 & 0.11 \\
\hline Thoracic bending angle $\left[^{\circ}\right]$ & 16.34 & 9.62 & 23.07 & 15.69 & 17.00 \\
\hline Lumbar bending angle $\left[^{\circ}\right]$ & 10.10 & 3.63 & 16.58 & 9.47 & 10.74 \\
\hline SD of the lateral deviation [mm] & $3.83^{*}$ & $1.33^{*}$ & $10.12^{*}$ & $3.33^{*}$ & $4.00^{*}$ \\
\hline Maximal lateral deviation [mm] & $-3.16^{*}$ & $-15.92^{*}$ & $13.31^{*}$ & $-5.00^{*}$ & $0.67^{*}$ \\
\hline SD rotation $\left[^{\circ}\right]$ & $3.67^{*}$ & $1.54^{*}$ & $9.71^{*}$ & $3.00^{*}$ & $4.00^{*}$ \\
\hline Maximal rotation $\left[^{\circ}\right]$ & -4.17 & $-16.46^{*}$ & $12.58^{*}$ & $-6.00^{*}$ & $1.67^{*}$ \\
\hline Kyphosis angle $\left[^{\circ}\right]$ & 45.85 & 27.24 & 64.46 & 44.03 & 47.67 \\
\hline Lordosis angle $\left[{ }^{\circ}\right]$ & $30.67^{*}$ & $9.83^{*}$ & $47.75^{*}$ & $29.33^{*}$ & $32.00^{*}$ \\
\hline
\end{tabular}

SD - standard deviation; * non-parametrical values. 
implied that there were no obvious differences in the inclination between the upper and lower body (Tables 1-3).

The thoracic bending angle was calculated from the distance between the vertebra prominens and the kyphosis apex, and indicated the deviation from the perpendicular line. The median angle was $16.24^{\circ}$, confirming the expected thoracic kyphosis. Here, wider variations were indicated by a tolerance range varying by $7^{\circ}$ and a CI varying by $0.6^{\circ}$. Similar variations of the tolerance range and the CIs were seen in the lumbar region with a flection angle on average $10.10^{\circ}$ (tolerance range: $3.63-16.58^{\circ} ; \mathrm{CI}=9.47-10.74^{\circ}$ ). The lumbar bending angle describes the deviation of the distance between the lordosis- and kyphosis apex.

Measurement of the standard deviation (SD) of the lateral deviation showed a right-sided inclination of the median line by $3.83^{\circ}$ when connecting the points vertebra prominens (VP) and the center of the pelvic markers. Both the tolerance range $\left(1.33-10.12^{\circ}\right)$ as well as the CI $\left(3.33-4^{\circ}\right)$ indicated a right-sided deviation.

The SD of the rotation of the spinal column is a marker of the spinal torsion, considering the direction of the spinous processes of vertebrae. A negative value describes a rotation to the left and a positive value to the right. The median rotation was $3.67^{\circ}$, with a tolerance range between 1.54 and $9.71^{\circ}$, and a CI between 3 and $4^{\circ}$. Consequently, on average a right-sided spinal rotation was found.

The next 2 parameters, the kyphosis and lordosis angle, had a mean or a median of $45.85^{\circ}$ and $30.67^{\circ}$, respectively, with a substantial tolerance range of approx. $\pm 19^{\circ}$ and a CI of about $\pm 1.5^{\circ}$.

Shoulder parameters are good indicators for upper body posture; in Table 5 parameters for shoulder position are compiled, including values for the tolerance ranges and the CIs.
The lower spine parameters of the scapula were additionally measured from the fixed markers; the scapula distance value as an indicator of the variability of the upper body was $179.23 \mathrm{~mm}$, with a tolerance range of $130.24-228.22 \mathrm{~mm}$ and a $\mathrm{CI}=174.45-184.01 \mathrm{~mm}$. The scapular height (deviation from the horizontal line) refers to a slightly lower left shoulder blade $\left(3^{\circ}\right)$, whereas the upper and lower limit of the tolerance range were $22.67^{\circ}$ and $15.29^{\circ}$, respectively. In contrast, the limit of the tolerance range was the data of the CI in the negative range, so the left shoulder blade was always located more caudally.

The rotation of the shoulder markers illustrated a minimally more dorsally located right shoulder $\left(0.52^{\circ}\right)$, with a tolerance range of $-5.90-6.94^{\circ}$ and a CI of $-0.10-1.15^{\circ}$. Only minor differences between the left and right shoulder blade angle show that the right shoulder was located $3^{\circ}$ (median) more caudally.

The pelvic position anchors the body and is also influenced by the feet length (differences). Table 6 compiles the parameters found for the pelvis, measured by the back scanner. The distance for the fixed markers on the SIPS refers to the pelvic width, which is on average $93.68 \mathrm{~mm}$ (tolerance range: $71.34-116.01 \mathrm{~mm}$; $\mathrm{CI}=91.50-95.86 \mathrm{~mm}$ ).

The deviation of the pelvic height (in degrees) identifies the horizontal plane and deviations from it. Both differences in pelvic height (in $\mathrm{mm}$ ) and deviations from the horizontal line (in degrees) indicate a slightly higher position of the left pelvic side (Tables 1-3).

The same applies to the pelvis torsion and rotation, so that the iliac left is further rotated posteriorly and simultaneously tilted further ventrally (mean pelvis torsion: $-0.43^{\circ}$; mean pelvic rotation: $-0.86^{\circ}$ ).

Table 5. Shoulder parameters: mean value, median, tolerance ranges (upper and lower limit), confidence intervals (Cls) (left and right limit)

\begin{tabular}{|l|c|c|c|c|c|}
\multicolumn{1}{|c|}{ Shoulder parameter } & Mean value/median & $\begin{array}{c}\text { Tolerance range } \\
\text { lower limit }\end{array}$ & $\begin{array}{c}\text { Tolerance range } \\
\text { upper limit }\end{array}$ & Cl left limit & Cl right limit \\
\hline Scapular distance $[\mathrm{mm}]$ & 179.23 & 130.24 & 228.22 & 174.45 & 184.01 \\
\hline Scapular height $\left[{ }^{\circ}\right]$ & $-3.00^{*}$ & -22.67 & 15.29 & -4.33 & -0.67 \\
\hline Scapular rotation $\left[{ }^{\circ}\right]$ & 0.52 & -5.90 & 6.94 & -0.10 & 1.15 \\
\hline Scapular angle left $\left[{ }^{\circ}\right]$ & $26.00^{*}$ & -29.75 & 44.92 & 24.67 & 27.00 \\
\hline Scapula angle right $\left[{ }^{\circ}\right]$ & $29.00^{*}$ & -31.12 & 48.79 & 27.67 & 29.67 \\
\hline
\end{tabular}

* non-parametrical values.

Table 6. Pelvis parameters: mean value, median, tolerance ranges (upper and lower limit), confidence intervals (Cls) (left and right limit)

\begin{tabular}{|l|c|c|c|c|c|}
\hline \multicolumn{1}{|c|}{ Pelvis parameter } & Mean value/median & $\begin{array}{c}\text { Tolerance range } \\
\text { lower limit }\end{array}$ & $\begin{array}{c}\text { Tolerance range } \\
\text { upper limit }\end{array}$ & Cl left limit & Cl right limit \\
\hline Pelvis distance [mm] & 93.68 & 71.34 & 116.01 & 91.50 & 95.86 \\
\hline Pelvis height [ $\left.{ }^{\circ}\right]$ & -0.77 & -5.27 & 3.73 & -1.21 & -0.33 \\
\hline Pelvis height [mm] & -1.24 & -8.61 & 6.13 & -1.96 & -0.52 \\
\hline Pelvis torsion $\left[{ }^{\circ}\right]$ & -0.43 & -10.83 & 9.97 & -1.45 & 0.58 \\
\hline Pelvis rotation $\left[{ }^{\circ}\right]$ & -0.86 & -8.06 & 6.33 & -1.56 & -0.16 \\
\hline
\end{tabular}

* non-parametrical values. 


\section{Discussion}

This paper presents normal values (tolerance range and CI) for body posture of healthy young males. All participants were young, healthy men, both students and employees.

Height, weight and BMI of the participants are comparable to those of the average young German males. ${ }^{22}$ Mensink et al. measured over 700 adults from the general German population, who were $1.02 \mathrm{~cm}$ smaller, $2.4 \mathrm{~kg}$ heavier, and thus also had by $0.9 \mathrm{~kg} / \mathrm{m}^{2}$ higher BMI, within the CI of the presented values. $^{22}$ Similar findings were reported by the German Federal Statistical Office in 2011 for the survey year of $2009 .^{23}$

Standard values from a homogeneous group of subjects eliminate constitutional, habitual and degenerative changes that increase both the tolerance range and CI. ${ }^{24-27}$ This prevents comparisons of studies in which such factors may have an influence on the habitual posture. A similar approach, using a homogenous group of healthy individuals for comparison purposes, was used in the definition of osteoporosis by bone density, where healthy, 30-year-old males were selected. ${ }^{28,29}$ Sex and age differences are known factors in bone density, as well as other factors, like TMD and temporomandibular dysfunctions. Possible reasons have been postulated in hormone levels, ${ }^{24}$ pain perception $^{25,27}$ and connective tissue properties. ${ }^{26}$

Among the participants of this study, $77 \%$ had a normal BMI, about 15\% higher than Mensink et al. found for 18-29-year-old men. ${ }^{22}$ Since these authors investigated the relation of overweight with social status, this selection may have been a confounder in their results. The German Federal Statistical Office did not collect such data. The differences in BMI may also be explained with the selection of the participants from the school of dentistry, which indicates a higher social status.

The values of the back scan indicated a characteristic posture. Only small deviations from an ideal perpendicular position were noted; the lateral deviation and rotation of the spine were very small; the ventral trunk tilted marginally to the right side, with a compensatory lumbar left tilt. All values included exact perpendicular position in the CI. The spinous processes of the spinal column were marginally twisted to the right (SD of the rotation), too (Table 4). The spinal curves, defined by the thoracic or lumbar flexion angle, and the kyphosis and lordosis angle, indicated that the angle in the thoracic spine area is larger than that in the lumbar region (Table 4) and, consequently, a more kyphotic posture in the sagittal plane could be observed. The posture was slightly scoliotic, with rotation component (scapular depression left, right scapula marginally located more dorsally, high state of pelvic left, iliac left further rotated posteriorly and simultaneously tilted further ventrally). The influence of handedness could be excluded in the parameters. However, it must be considered that no balance between left- and right-handed subjects could be seen, since the majority of the study participants reported to be right-handed (91.2\%). Whether there is an influence of the dominating leg or of one's preferred chewing side on the posture of the present investigation, cannot be answered..$^{30-33}$ An appropriate test method for determining these components should be used in further studies on the same topic.

The 3-dimensional back scan is a fast, non-contact method to calculate body posture and movement. This method is suitable for measuring pathological body postures, like attitude pathologies, scoliosis, kyphosis, leg length differences, and functional movement disorders. Sensitivity and specificity of the video raster stereographic survey is $98 \%$ and $84 \%$, respectively. The data proportion of false-positive values is $13.9 \% .{ }^{34}$ Furthermore, Drerup and Hierholzer showed a strong correlation between the system of raster stereography and radiological angles with a correlation coefficient of $0.8-0.93 .{ }^{35,36}$ Hübner found a highly variable perpendicular deflection as well as kyphosis and lordosis angles; however, that study used a system from a different manufacturer. ${ }^{37}$ The data differences indicate the need for calibrating values when comparing kinematic values obtained with different technical systems.

All participants were encouraged to assume the same posture to prevent differences in position, which could influence vertebral and surface rotations. ${ }^{38}$ To reduce motion artifacts, multiple measurements were carried out, and the average values from 2-minute measurements were used for the analysis. Another possible influence factor is the accuracy of the anatomical marker fixation. Drerup and Hierholzer found a 1-millimeter variation of the lumbar spine dimple. ${ }^{39}$

Measuring exactly the back surface in overweight subjects is described by Asamoah et al. ${ }^{34}$ They observed a significantly lower correlation between video raster stereography and X-ray measurements with a correlation coefficient of 0.56. Furthermore, they mentioned that the constitution had an impact on the accuracy of the data, but without quantifiable factors. Since in the present study $77 \%$ of the participants were of normal weight, this artifact was less relevant. It cannot be conclusively confirmed whether the back geometry of the remaining volunteers with an increased BMI was detected accurately with the system.

The system used in the present study allows for correction with manually placed markers. Correcting the measurements in this way after scanning resulted in deviations of up to $\pm 5 \mathrm{~mm}$, as quantified in a study with a different back scanner. ${ }^{40}$ In order to quantify the precision of the markers on a subject, the back side anatomical landmarks were positioned 12 times on the back of 1 individual under the same conditions (unpublished results). The markers could be placed with a standard deviation of $0.91 \%$. Thus, a maximal error from marking and data evaluation of $2 \%$ can be safely assumed.

Video raster stereography is a suitable method to measure the 3-dimensional back surface. Using this method for healthy young men ensures that they have an almost ideally balanced posture, with minimal ventral body inclination and a marginal scoliotic deviation. The normal values allow a comparison of other control and patient data. 


\section{References}

1. Hairston LE, Blanton PL. An electromyographic study of mandibular position in response to changes in body position. J Prosthet Dent. 1983;49(2):271-275.

2. Leiva M, Miralles R, Palazzi C, et al. Effects of laterotrusive occlusal scheme and body position on bilateral sternocleidomastoid EMG activity. Cranio. 2003;21(2):99-109.

3. Miralles R, Gutierrez C, Zucchino G, et al. Body position and jaw posture effects on supra- and infrahyoid electromyographic activity in humans. Cranio. 2006;24(2):98-103.

4. Palazzi C, Miralles R, Soto MA, Santander $H$, Zuniga $C$, Moya H. Body position effects on EMG activity of sternocleidomastoid and masseter muscles in patients with myogenic cranio-cervical-mandibular dysfunction. Cranio. 1996;14(3):200-209.

5. Saito ET, Akashi PM, Sacco Ide C. Global body posture evaluation in patients with temporomandibular joint disorder. Clinics (Sao Paulo). 2009;64(1):35-39.

6. Van't Spijker A, Creugers NH, Bronkhorst EM, Kreulen CM. Body position and occlusal contacts in lateral excursions: A pilot study. Int J Prosthodont. 2011;24(2):133-136.

7. Korbmacher H, Koch L, Eggers-Stroeder G, Kahl-Nieke B. Associations between orthopaedic disturbances and unilateral crossbite in children with asymmetry of the upper cervical spine. Eur JOrthod. 2007;29(1):100-104.

8. Saccucci M, Tettamanti L, Mummolo S, Polimeni A, Festa F, Tecco S. Scoliosis and dental occlusion: A review of the literature. Scoliosis. 2011;6:15. doi: 10.1186/1748-7161-6-15

9. Wachsman K. Über den Zusammenhang der Gebißanomalien mit Krümmungen der Wirbelsäule und schlaffer Körperhaltung. Fortschr Kieferorthop. 1960;21(4):449-453.

10. Lippold C, Ehmer U, Van Den Boos L. Beziehungen zwischen kieferorthopädischen und orthopädischen Befunden. Manuelle Medizin. 2000;38:346-350.

11. Fink M, Tschernitschek $H$, Stiesch-Scholz M. Asymptomatic cervical spine dysfunction (CSD) in patients with internal derangement of the temporomandibular joint. Cranio. 2002;20(3):192-197.

12. Fink $M$, Wahling $K$, Stiesch-Scholz $M$, Tschernitschek $H$. The functional relationship between the craniomandibular system, cervical spine, and the sacroiliac joint: A preliminary investigation. Cranio. 2003;21(3):202-208.

13. Bazzocchi A, Ponti F, Diano D, et al. Trabecular bone score in healthy ageing. Br J Radiol. 2015;88(1052):20140865. doi: 10.1259/bjr.20140865

14. Perry J, Burnfield JM. Gait Analysis. Thorofare, NJ: Slack Incorporated; 2010.

15. Götz-Neumann K. Gehen Verstehen: Ganganalyse in der Physiotherapie. Stuttgart, Germany: Thieme Verlag; 2011.

16. Marini I, Alessandri Bonetti G, Bortolotti F, Bartolucci ML, Gatto MR Michelotti A. Effects of experimental insoles on body posture, mandibular kinematics and masticatory muscles activity: A pilot study in healthy volunteers. J Electromyogr Kinesiol. 2015;25(3):531-539.

17. Marini I, Gatto MR, Bartolucci ML, Bortolotti F, Alessandri Bonetti G, Michelotti A. Effects of experimental occlusal interference on body posture: An optoelectronic stereophotogrammetric analysis. J Oral Rehabil. 2013;40(7):509-518.

18. Nobili A, Adversi R. Relationship between posture and occlusion: A clinical and experimental investigation. Cranio. 1996;14(4):274-285.

19. Sinko K, Grohs JG, Millesi-Schobel G, et al. Dysgnathia, orthognathic surgery and spinal posture. Int J Oral Maxillofac Surg. 2006;35(4):312-317.

20. Obesity: Preventing and managing the global epidemic. Report of a WHO Consultation (WHO Technical Report Series 894). http:// www.who.int/nutrition/publications/obesity/WHO_TRS_894/en/. Published 2000. Accessed January 1, 2017.
21. Kopp S. Okklusale und klinisch funktionelle Befunde im cranio-mandibulären System bei Kindern und Jugendlichen. Friedrich-SchillerUniversität Jena; 2005.

22. Mensink GBM, Schienkewitz A, Haftenberger M, Lampert T, Ziese T, Scheidt-Nave C. Übergewicht und Adipositas in Deutschland. Bundesgesundheitsblatt. 2013;56:786-794.

23. Statistiches Bundesamt. Mikrozensus - Fragen zur Gesundheit Körpermaße der Bevölkerung. https://www.destatis.de/DE/Publikationen/Thematisch/Gesundheit/Gesundheitszustand/Koerpermasse5239003139004.pdf?__blob=publicationFile. Published 2013. Accessed January 12, 2017.

24. Abubaker AO, Raslan WF, Sotereanos GC. Estrogen and progesterone receptors in temporomandibular joint discs of symptomatic and asymptomatic persons: A preliminary study. J Oral Maxillofac Surg. 1993;51(10):1096-1100.

25. Bush FM, Harkins SW, Harrington WG, Price DD. Analysis of gender effects on pain perception and symptom presentation in temporomandibular pain. Pain. 1993;53(1):73-80.

26. Conti PC, Ferreira PM, Pegoraro LF, Conti JV, Salvador MC. A crosssectional study of prevalence and etiology of signs and symptoms of temporomandibular disorders in high school and university students. J Orofac Pain. 1996;10(3):254-262.

27. Nordstrom G, Eriksson S. Longitudinal changes in craniomandibular dysfunction in an elderly population in northern Sweden. Acta Odontol Scand. 1994;52(5):271-279.

28. Kanis JA, Melton LJ, Christiansen C, Johnston CC, Khaltaev N. The diagnosis of osteoporosis. J Bone Miner Res. 1994;9(8):1137-1141.

29. Kanis JA; WHO Study Group. Assessment of fracture risk and its application to screening for postmenopausal osteoporosis: Synopsis of a WHO report. Osteoporos Int. 1994;4(6):368-381.

30. Fischer K. Rechts-Links-Probleme in Sport und Training. Studien zur angewandten Lateralitätsforschung. Schorndorf, Germany: Hofmann Verlag; 1988.

31. Paphangkorakit J, Chaiyapanya N, Sriladlao P, Pimsupa S. Determination of chewing efficiency using muscle work. Arch Oral Biol. 2008;53(6):533-537.

32. Martinez-Gomis J, Lujan-Climent M, Palau S, Bizar J, Salsench J, Peraire $M$. Relationship between chewing side preference and handedness and lateral asymmetry of peripheral factors. Arch Oral Biol. 2009;54(2):101-107.

33. Ratnasari A, Hasegawa K, Oki K, et al. Manifestation of preferred chewing side for hard food on TMJ disc displacement side. J Oral Rehabil. 2011;38(1):12-17.

34. Asamoah V, Mellerowicz H, Venus J, Klockner C. Measuring the surface of the back. Value in diagnosis of spinal diseases. Orthopade. 2000;29(6):480-489.

35. Drerup B. Improvements in measuring vertebral rotation from the projections of the pedicles. J Biomech. 1985;18(5):369-378.

36. Drerup B, Hierholzer E. Objective determination of anatomical landmarks on the body surface: Measurement of the vertebra prominens from surface curvature. J Biomech. 1985;18(6):467-474.

37. Hübner J. Handbook Formetric III. Schlangenbad, Germany: Diers International $\mathrm{GmbH} ; 2007$.

38. Hierholzer E. Objektive Analyse der Rückenform von Skoliosepatienten. Stuttgart, Germany: Gustav Fischer Verlag; 1993.

39. Drerup B, Hierholzer E. Automatic localization of anatomical landmarks on the back surface and construction of a body-fixed coordinate system. J Biomech. 1987;20(10):961-970.

40. Diers H. Optische Wirbelsäulen- und Haltungsvermessung. Orthopädie Technik. 2008;38:479-484. 